\title{
Laser induced damage of multilayer coatings for 248 nm
}

\author{
Hongji QI, Kui YI, Jingmei YUAN, Hua YU, Jianda SHAO, and Zhengxiu FAN \\ Shanghai Institute of Optics and Fine Mechanics, Chinese Academy of Sciences, Shanghai 201800, China
}

(Received January 28, 2008)

\begin{abstract}
Antireflection coatings (AR), beam splitter coatings (BS) and high-reflectance coatings (HR) were prepared to study the effect of material properties and stack structures on the laser induced damage behaviors of coatings at a wavelength of $248 \mathrm{~nm}$. All the coatings were deposited on fused silica substrates by electron beam reactive evaporation technique with the materials of aluminum oxide and silicon dioxide. Laser-induced damage thresholds (LIDTs), damage morphologies and profiles of damage sites of multilayer coatings were characterized to investigate the damage mechanism of coatings irradiated by the excimer laser. Besides, the temperature fields were calculated to better understand the damage mechanism with our programmed software. The results indicate that the absorption of defects and the electric field distribution of thin film greatly contribute to LIDTs of thin films.
\end{abstract}

Key Words: Laser induced damage, Excimer laser, Antireflection coating, Beam splitter coating and high-reflectance coating

\section{Introduction}

Excimer laser systems have been widely used in many fields, e.g., medical science ${ }^{1,2)}$, micromachining ${ }^{3,4)}$, laser annealing ${ }^{5,6)}$, and deposition of thin film ${ }^{7,8)}$. However, many applications suffer from the limited resistance of optical components against intense laser radiation. Optimizing the LIDTs of optical components is critical when developing the cost-effective excimer laser system. In the UV region, the transparent materials include several metal oxide/ $\mathrm{SiO}_{2}$ combinations, large bandgap fluoride combinations, and metal oxide/fluoride combinations. The reported LIDT values of $\mathrm{KrF}$ $(248 \mathrm{~nm})$ reflectors consisting of oxide layers are about $10 \mathrm{~J} / \mathrm{cm}^{2}$ (Ref.9) and $16 \mathrm{~J} / \mathrm{cm}^{2}$ (Ref.10), respectively. In general, absorption by host materials and imperfections are the limiting factor for the optics especially in the UV spectral region ${ }^{11)}$. In this work, $\mathrm{Al}_{2} \mathrm{O}_{3} / \mathrm{SiO}_{2}$ multilayer $\mathrm{AR}$, $\mathrm{BS}$ and $\mathrm{HR}$ coatings for $248 \mathrm{~nm}$ were deposited to investigate the role of host materials and absorbing defects in the laser induced damage of coatings.

\section{Preparation and characterization of multilayer coatings}

With optimized parameters, AR, BS and HR coatings for $248 \mathrm{~nm}$ were reactively deposited by electron beam evaporation in a laboratory ZZSX-800F coating plant with a refrigerator cryopump and a cold trap. The coating designs are simply G/(ML) $)^{2} /$ air, G/(ML) ${ }^{5} \mathrm{M} /$ air, and $\mathrm{G} /(\mathrm{ML})^{20} \mathrm{M} /$ air, for $\mathrm{AR}, \mathrm{BS}$ and $\mathrm{HR}$ coatings, respectively, where $\mathrm{M}$ is quarterwave layer $\mathrm{Al}_{2} \mathrm{O}_{3}$, $\mathrm{L}$ is quarterwave layer $\mathrm{SiO}_{2}$, and $\mathrm{G}$ is substrate fused silica ( $30 \mathrm{~mm}$ diameter, $3 \mathrm{~mm}$ thickness). The substrates were ultrasonic cleaned under class 1000 clean room conditions. Before deposition, the chamber was pumped to a base pressure of $2 \times 10^{-3} \mathrm{~Pa}$. The substrate holder was kept at $570 \mathrm{~K}$ during the deposition process. Ultrahigh purity $\mathrm{O}_{2}$ (99.99\%) was used to get a background pressure of $2 \times 10^{-2} \mathrm{~Pa}$ with mass flow meter. The inlet of oxygen was located nearby the substrate holder to keep the stoichiometry of thin films. Film thicknesses and deposition rates were monitored by an optical monitoring system and a crystal oscillator, respectively.
The deposition rates were about $0.35 \mathrm{~nm} / \mathrm{s}$ and $0.66 \mathrm{~nm} / \mathrm{s}$ for $\mathrm{Al}_{2} \mathrm{O}_{3}$ and $\mathrm{SiO}_{2}$.

The LIDTs of multilayer coatings were characterized with $\mathrm{KrF}$ laser damage testing facility (almost flat-topped, $25 \mathrm{~ns}$, $1 \mathrm{H}_{\mathrm{Z}}$, effective beam size $1.1 \mathrm{~mm} \times 1.1 \mathrm{~mm}$ ) in 1-on- 1 and s-on-1 test modes, following ISO standard $11254{ }^{12)}$. The morphologies and depths of damage sites were examined with in situ UV-Vis CCD detection and ex situ Nomarski optical microscope (magnification from $\times 50$ to $\times 500$ ), atomic force microscope with scanning areas ranging from $50 \times 50 \mathrm{um}^{2}$ to $80 \times 80 \mathrm{um}^{2}$.

\section{Results and Discussion}

With the maximum influence of $10 \mathrm{~J} / \mathrm{cm}^{2}$, AR and BS coatings presented no damage after 10 shots. However, HR coatings were relatively senstive to the laser radition, and appeared to be obvious damage after several shots at $7 \mathrm{~J} / \mathrm{cm}^{2}$. With the 1-on-1 test procedure, laser damage probability curve of HR coatings were obtained and the damage thresholds of zero-probability were determined to be about $5 \mathrm{~J} / \mathrm{cm}^{2}$. The morphologies of damage sites were examined with Nomarski optical microscope and the typical one is shown in Fig.1. The damage spot include the scattered damage sites and the center scald zone, surrounded with the uniform purple ring-like zone. Besides, atomic force microscope (Digital Instruments, Dimension 3100) was used to get the nano-level information of damage sites. Compared with damage spots, the scanning area of AFM is dissatisfactory. Therefore, the tip of AFM is located near the edge of damage spot. Fig. 3 illustrates two-dimensional surface image of the damage spot with scan size $50 \times 50 \mathrm{um}^{2}$. The left rough region and the right relative smooth region are damaged and undamaged surface of coating. As seen from Fig.3, several distinct damage morphologies, such as pit, scald and outer layer delamination, were observed. The corresponding one-dimension cross-section scan of surface profile are plotted in Fig. 4 and the arrow in Fig. 3 labels the position of the one-dimension scan. As shown in Fig.4, the thickness of flat bottom pit is about $280 \mathrm{~nm}$. For HR 


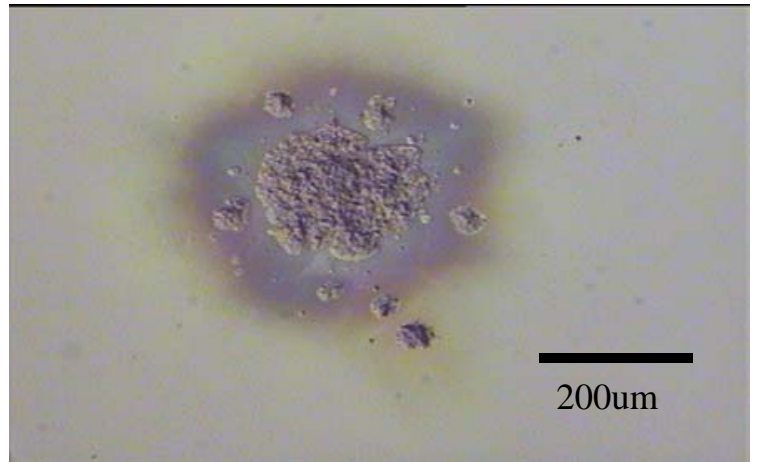

Fig.1 Nomarski optical micrograph of typical damage after 5 shots at $7 \mathrm{~J} / \mathrm{cm}^{2}$ for HR coating

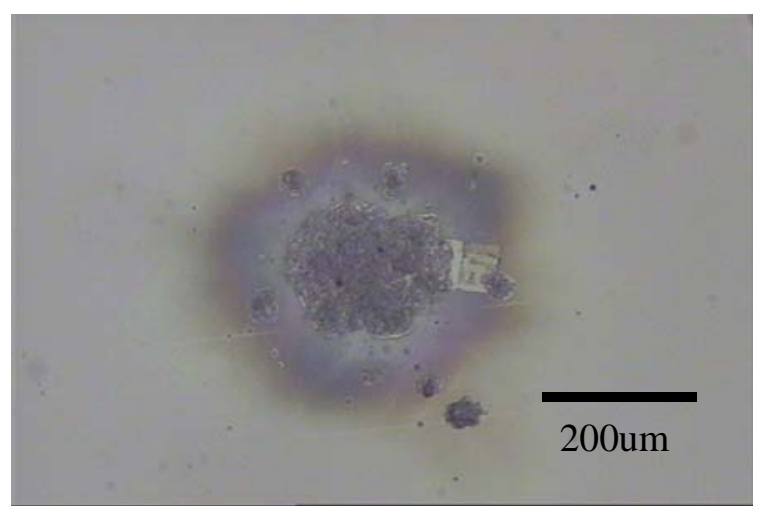

Fig.2 Nomarski optical micrograph of typical damage in Fig.1 after AFM measurement

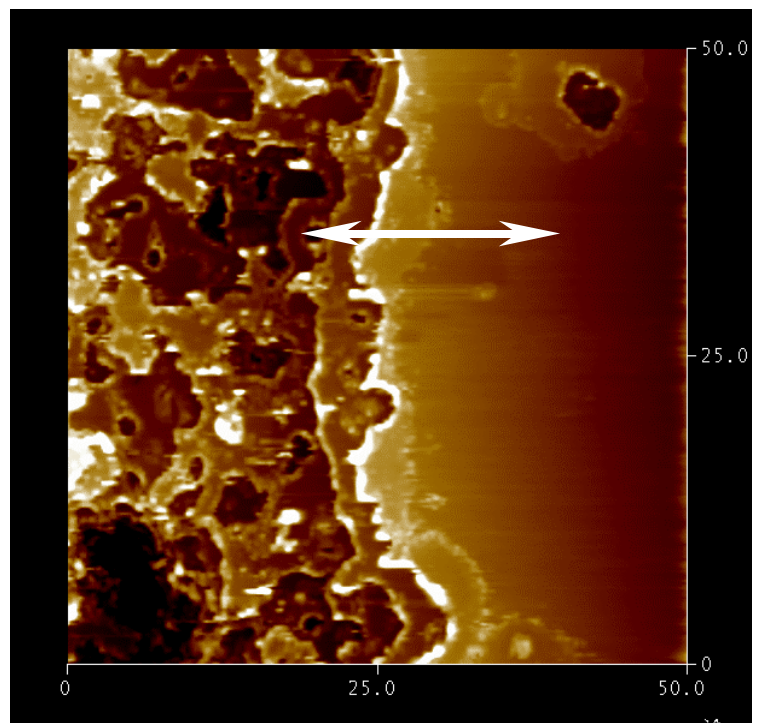

Fig.3 AFM image of the damage site for HR coating, Image is $512 \times 512$ with scan size $50 \times 50 \mathrm{um}^{2}$

coatings at $248 \mathrm{~nm}$, the combination physical thickness of $\mathrm{M}$ and $\mathrm{L}$ layers is about $80 \mathrm{~nm}$, that is to say, the outer layers of $3 \sim 4$ periods are removed under laser radiation. As is well known, the electric field of HR coatings decay along the multilayer from the incident sides, and the intense electric field locals at the outer layers of coating. After AFM measurement, the morphology of the same damage sites was examined with

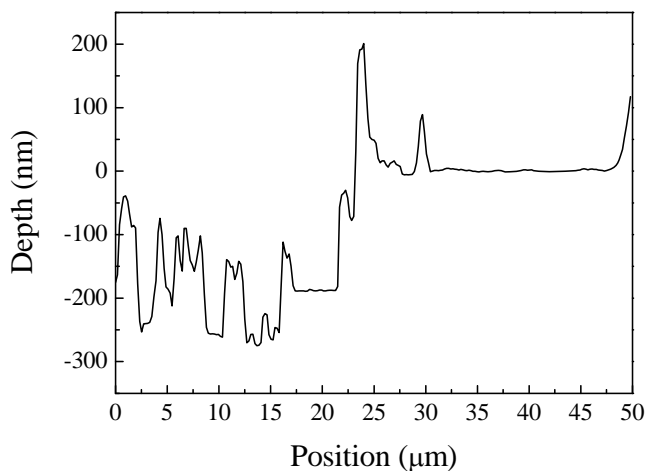

Fig.4 Cross-section scan of surface profile in Fig.3 leaded to the vaporization of materials. The vaporazied material was then cooled and adsorpted near damage site.

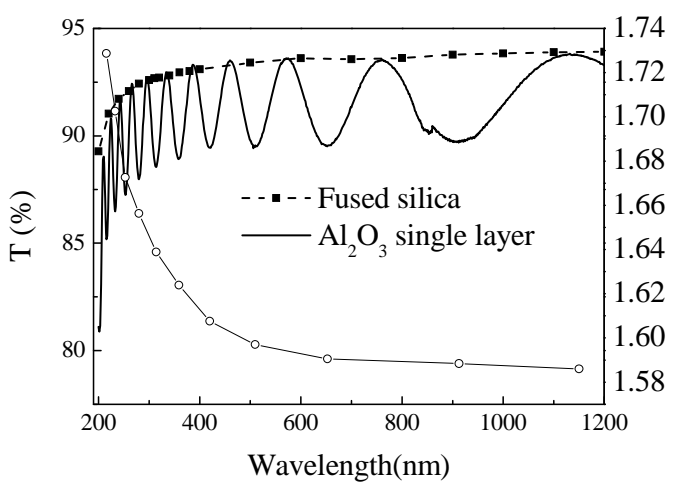

Fig.5 The transmittance curves of fused silica before and after the deposition of single layer of $\mathrm{Al}_{2} \mathrm{O}_{3}$ and the fitted refractive index of $\mathrm{Al}_{2} \mathrm{O}_{3}$

Nomarski optical microscope, as shown in Fig.2 with a magnification of 50 . It's clear that there is a square scanning trace due to AFM measurement, which indicate that the uniform purple ring-like zone, surrounding the center scald zone of damage site, is an adsorption layer and can be scratched by AFM tips. So, the thermal process played a great role in the damage of coating with violet laser radiation. Absorption energy of coating was converted to thermal, which leaded to the vaporization of materials. The vaporazied material was then cooled and adsorpted near the damage site.

In order to better understand the damage mechanism of the above multilayer coatings at $248 \mathrm{~nm}$, the electric field distribution and the temperature rise in the multilayers were calculated with our programmed software. Firstly, the single layers of $\mathrm{Al}_{2} \mathrm{O}_{3}$ and $\mathrm{SiO}_{2}$ were deposited on fused silica substrates with same deposition parameters. Then, transmittance measurements were performed in a spectral range spanning from UV to NIR (200-1200nm) with 
spectrophotometry (Perkin-Elmer UV/VIS/NIR Lambda 900) and an envelope method was used to estimate the dispersion of refractive indices and extinction coefficients of coating materials. In order to reduce the effect of fused silica substrate on the derived optical constants of coating materials, the transmittance of substrate was first measured before deposition of single layers. The transmittance curves of fused silica before and after the deposition of single layer of $\mathrm{Al}_{2} \mathrm{O}_{3}$ is shown in Fig.5. The transmittance of fused silica is decreasing due to the dispersion of refractive index and increasing weak absorption for shorter wavelength. For the wavelength longer than $300 \mathrm{~nm}$, the transmittance of fused silica is an upper envelope of interference fringe of single layer. However, for the shorter wavelength, the transmittance of fused silica is distinctly higher than the upper envelope of interference fringe of single layer due to the intrinsic absorption of coating material. Finally, our programmed software was applied to further determine the optical constants of the films by fitting calculated data to measured spectral curve. At $248 \mathrm{~nm}$, the absorption coefficient is 0.0001 and 0.00005 for $\mathrm{Al}_{2} \mathrm{O}_{3}$ and $\mathrm{SiO}_{2}$ layers, which are similar to those in the reference ${ }^{13)}$. With the obtained absorption coefficient and other relevant parameters listed in table 1 , the temperature rise in the multilayer coatings was calculated to better understand the damage mechanism at 248nm, as shown in Fig.6.

As seen from Fig.6 (a) (c), the maximum temperature rise in the multilayer is near the surface of coatings, to be about $130 \mathrm{~K}, 110 \mathrm{~K}$ and $95 \mathrm{~K}$ for AR, BS and HR coatings, respectively.

For AR and BS coatings, the temperature rise is below $150 \mathrm{~K}$, which can explain the non-damage behavior under the laser radiation. However, the temperature rise of HR coating is lowest among all of coatings, which is inconsistent with the behavior of the relatively senstive to laser radition.

As shown in Fig.1 and Fig.2, HR coatings were damaged by the defect-absorption induced melting and vaporization of the coating material, even outer layer delamination. Generally, compared with the host material, the absorption of defect is relatively higher, even by several orders of magnitude in the UV region. For convenience, it's simple to raise the absorption of host material to investigate the effect of defects on damage of thin films. Fig. 6 (d) plots the temperature distribution in the multilayers with the same parameters listed in table 1 except for the extinction coefficient $\quad k_{A}=0.0005$ of $\mathrm{Al}_{2} \mathrm{O}_{3}$.

The calculated temperature rise is almost $500 \mathrm{~K}$ at the incident fluence of $7 \mathrm{~J} / \mathrm{cm}^{2}$. With the help of the stresses generated in coating with laser radiation, the above instantaneous temperature rise was sufficient to generate damage of coating. Besides, the non-linear effects of absorption of defects and host material deteriorate the damage behavior for HR coatings.

Compared with AR and BS coatings, the more layer number of HR coating means more imperfections in coating. Besides, the deposited coating material near the electron gun became the new contamination source in the following deposition. As the deposition going, this type of contamination source played more and more important role in introducing inclusions into coatings. Moreover, the intense electric field locals at the outer layers for HR coatings. The intense electric field and stong absorption of defect in the outer layers both contribute to the brittle damage resistant capability of HR coatings.
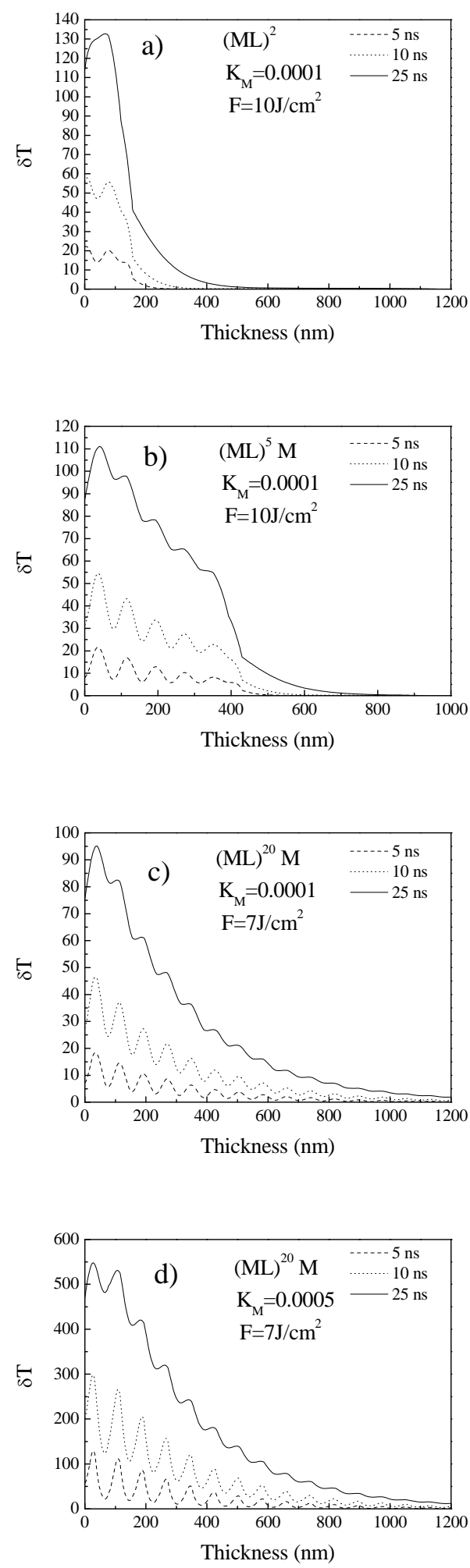

Fig.6 Calculated temperature distribution in the multilayer stacks at $5 \mathrm{~ns}, 10 \mathrm{~ns}$ and $25 \mathrm{~ns}$ with the incident fluences of $10 \mathrm{~J} / \mathrm{cm}^{2}$ for AR, BS coatings and $7 \mathrm{~J} / \mathrm{cm}^{2}$ for HR coatings 
Table 1 Material properties of silica, alumina and fused silica used for numerical calculation of thermal response of the multilayer stacks.

\begin{tabular}{|l|l|l|l|l|}
\hline Parameter & Unit & $\mathrm{SiO}_{2}$ & $\mathrm{Al}_{2} \mathrm{O}_{3}$ & $\mathrm{G}$ \\
\hline $\begin{array}{l}\text { Thermal } \\
\text { conductivity }\end{array}$ & $\begin{array}{l}\left({\mathrm{W} . \mathrm{m}^{-1}}^{-1}\right) \\
. \mathrm{K}^{-1}\end{array}$ & $0.1^{14)}$ & $0.25^{14)}$ & $1.38^{15)}$ \\
\hline $\begin{array}{l}\text { Heat } \\
\text { capacity }\end{array}$ & $\begin{array}{l}\left(\mathrm{J}_{\mathrm{Kg}}^{-1}\right. \\
\left.. \mathrm{K}^{-1}\right)\end{array}$ & $700^{16)}$ & $777^{15)}$ & $746^{15)}$ \\
\hline \multicolumn{1}{|c|}{ Density } & $\begin{array}{l}\left(\mathrm{Kg}^{15} \mathrm{~m}\right. \\
-3\end{array}$ & $2200^{16)}$ & $3980^{15)}$ & $2200^{15)}$ \\
\hline $\mathrm{n}$ & --- & 1.474 & 1.692 & 1.5 \\
\hline $\mathrm{k}$ & --- & 0.00005 & 0.0001 & 0 \\
\hline $\mathrm{d}$ & --- & $42 \mathrm{~nm}$ & $36.6 \mathrm{~nm}$ & $3(\mathrm{~mm})$ \\
\hline
\end{tabular}

\section{Conclusions}

With e-beam evaporation technique, $\mathrm{Al}_{2} \mathrm{O}_{3} / \mathrm{SiO}_{2}$ multilayer AR, BS and HR coatings for $248 \mathrm{~nm}$ were reactively deposited to investigate the damage mechanism for $\mathrm{KrF}$ excimer laser. With the maximum fluence of $10 \mathrm{~J} / \mathrm{cm}^{2}$, AR and BS coatings presented no damage after 10 shots. However, HR coatings appeared to be abvious damage after several shots at $7 \mathrm{~J} / \mathrm{cm}^{2}$. Using Nomarski optical microscope and AFM microscope, the damage sites were characterized. Besides, the temperature rise in the multilayers was calculated to better understand the damage mechanism at $248 \mathrm{~nm}$. The calculated and experimental results show that the absorption of defects and electric field distribution contributed greatly to the damage of HR coatings at $248 \mathrm{~nm}$.

\section{Acknowledgments}

The authors gratefully acknowledge financial support of this work by the National Natural Science Foundation of China (60678004). The authors wish to thank Xiao Qiling in characterization of damage sites.

\section{References}

1) Al-Mutairi N, Dermatologic Surgery, 33 (2007) 1483.

2) Sivakumar M, Oliveira V, Vilar R, et al., Journal of Laser Applications, 18 (2006), 330.

3) Hocheng H, Wang KY, Applied Optics, 46 (2007) 7184.

4) Tsai HY, Ting CJ, Chou CP, Diamond and Related Materials, 16 (2007) 253

5) Matsuo N, Uejukkoku K, Heya A, et al, Japanese Journal of Applied Physics Part 2, 46 (2007) L1061.

6) Aoki H, Ohyama K, Sota H, et al, Applied Surface Science, 254 (2007) 596.

7) Sun Y, Doherty RP, Warren JL, et al, Chemical Physics Letters, , 447 (2007) 257.

8) Donnelly T, Doggett B, Lunney JG, Applied Surface Science, 252 (2006) 4445.

9) D. B. Harris, L.A. Roosocha and D.C. Cartwright, Proc. 3rd Inertial Confinement Fusion Systems and Applications, Madison, 1987.

10) N. Kaiser, H. Uhlig, U.B. Schallenberg, et al., Thin Solid Films, , 260 (1995) 86.

11) M. Reichling, A. Bodemann, N. Kaiser, Thin Solid Films, 320 (1998) 264.

12) Test method for laser induced damage threshold of optical surfaces, Part I: l-on-l test, ISO 11254.

13) R. Thielsch, A. Gatto, J. Heber, et al., Thin Solid Films, 410 (2002) 86.

14) Donald L Decker, SPIE, 1323 (1990) 244

15) Michael Bass, Eric W. Van Stryland, David R. Williams, William L. Wolfe, Handbook of Optics, Devices, Measurements, \& properties, (2rd Edition), 1995, 33.40-33.55

16) F. Y. Génin, C. J. Stolz, T. Reitter, et al., SPIE, 2966(1997) 342. 